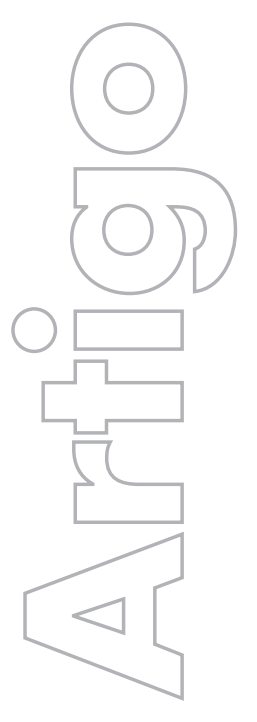

revista

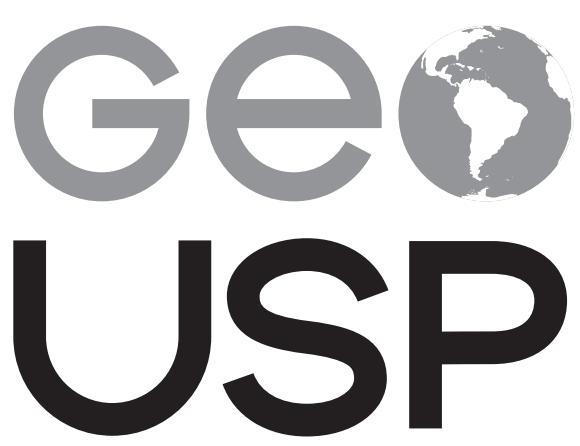

espaço e tempo

Volume $20 \cdot n^{\circ} 2(2016)$

ISSN 2179-0892

\section{Reestruturação}

metropolitana na Amazônia oriental: empreendimentos econômicos e dispersão urbana na área de influência imediata de Belém

Saint-Clair Cordeiro da Trindade Júnior UFPA

Estêvão José da Silva Barbosa UFPA

p. $349-363$

Como citar este artigo:

TRINDADE JR., S.-C. C. ; BARBOSA, E. J. S. Reestruturação metropolitana na Amazônia oriental: empreendimentos econômicos e dispersão urbana na área de influência imediata de Belém. Geousp - Espaço e Tempo (Online), v. 20, n. 2 , p. 349-363, mês. 2016. ISSN 2179-0892.

Disponível em: <http://www.revistas.usp.br/geousp/issue/ view/6465> . doi: http://dx.doi.org/10.11606/issn.2179-0892. geousp. 2014.84539.

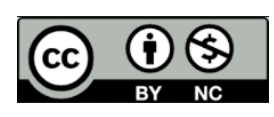

Este artigo está licenciado sob a Creative Commons Attribution 4.0 License. 


\title{
Reestruturação metropolitana na Amazônia oriental: empreendimentos econômicos e dispersão urbana na área de influência imediata de Belém
}

\section{Resumo}

O trabalho discute a repercussão de um complexo industrial-urbano-portuário instalado no município de Barcarena (estado do Pará), na Amazônia oriental brasileira, e as mudanças que imprime à área de influência imediata da metrópole belenense e em sua relação com ela. Constata-se que tais repercussão e mudanças têm concorrido para dar uma nova feição à metrópole de Belém, marcada simultaneamente por concentração e dispersão urbana e cujo dinamismo atual não mais se circunscreve aos limites da região metropolitana oficialmente reconhecida.

Palavras-chave: Reestruturação metropolitana. Dispersão. Concentração. Belém e Barcarena. Estado do Pará.

Metropolitan restructuring in Eastern Amazonia: economic enterprises and urban sprawl in the direct area of influence in the metropolis of Belem

\begin{abstract}
This paper discusses the repercussions of an Urban Industrial Port Complex that has been installed in the municipality of Barcarena, in the State of Para, which is located in the Eastern boundary of the Brazilian Amazon. It analyzes changes caused in the direct area of influence in the metropolis of Belem, as well as its relationship with Belem. It has been observed that the consequences and changes have contributed to metropolitan restructuring in Belem, which is marked, simultaneously, by concentration and urban sprawl. Belem's current dynamism does not confirm to the officially recognized boundaries of the metropolitan area.
\end{abstract}

Keywords: Metropolitan restructuring. Sprawl. Concentration. Belem and Barcarena. Para State. 


\section{Introdução}

A Região Metropolitana de Belém (RMB), estado do Pará, é um dos onze espaços metropolitanos oficialmente reconhecidos na Amazônia brasileira. Foi criada em 1973 com apenas dois municípios, Belém e Ananindeua. No ano de 1995, foi reconhecida uma nova configuração desse espaço, incluindo, além daqueles, os municípios de Marituba, Benevides e Santa Bárbara do Pará. Ainda mais recentemente, em 2010 e 2011, foram incluídos respectivamente os municípios de Santa Isabel do Pará e Castanhal (IBGE, 2014a).

Os processos que configuram a metropolização de Belém e seu entorno, entretanto, sugerem uma dinâmica que extrapola os limites geográficos oficiais, daí a necessidade de se entender tais processos e as especificidades que caracterizam os espaços metropolitanos nos dias atuais.

Para a presente análise, tomamos como referência um dos municípios limítrofes da Região Metropolitana oficial, o de Barcarena, bem como a dinâmica socioespacial em curso para discutir processos que tendem a apresentar uma nova reconfiguração do espaço metropolitano de Belém (Figura 1). A análise é realizada tendo em vista as repercussões socioespaciais decorrentes da instalação de um grande empreendimento que chamaremos aqui de complexo industrial-urbano-portuário de Barcarena, onde foi implantado, primeiramente, o projeto Albras-Alunorte. ${ }^{\prime}$ Os pressupostos da escolha de localização deste empreendimento incluem a proximidade da capital paraense, condições favoráveis à instalação de um porto exportador/ importador moderno com boas condições de calado, e o acesso a abundantes recursos minerais e hidroelétricos (Monteiro; Coelho; Barbosa, 2011).

As repercussões do empreendimento e as mudanças recentes pelas quais ele tem passado são analisadas no plano das relações que se estabelecem com o espaço metropolitano oficialmente reconhecido, contribuindo para definir uma nova feição da metrópole de Belém, dada a uma nova dinâmica socioespacial e de fluxos imprimidos em relação à capital paraense e a seu entorno a partir da instalação do complexo em Barcarena.

\section{A dinâmica metropolitana e a natureza do espaço socialmente produzido}

De início, é preciso retomar, à maneira de Buzenot ${ }^{2}$ (apud Lencioni, 2008) as noções de escalas topográfica e topológica que orientam a discussão atual sobre as dinâmicas metropolitanas e a reestruturação produtiva dos territórios. A primeira, a escala topográfica, diz respeito a atributos de natureza absoluta do espaço - medido em termos de superfície e de tempo de percurso - entre dois lugares, e tem como referência notadamente a rede de infraestrutura e de circulação. De maneira diferente, a escala topológica, tende a considerar os espaços em suas relações, relativizando o longe e o perto, incluindo também a lógica virtual, à semelhança do que foi chamado de espaço relacional por Harvey (1980).

\section{Figura 1 - Mapa da Região Metropolitana de Belém e seu entorno}

1 Siglas das empresas Alumínio Brasileiro S/A e Alumina do Norte do Brasil S/A, respectivamente.

2 BUZENOT, L. Demarche du géographie et raisonnement multiscalaire. Histgeo, 2007. Disponível em: <http:/histgeo. ac-aix-marseille.fr/a/div./d043.htm>. Acesso em: 8 nov. 2016. 


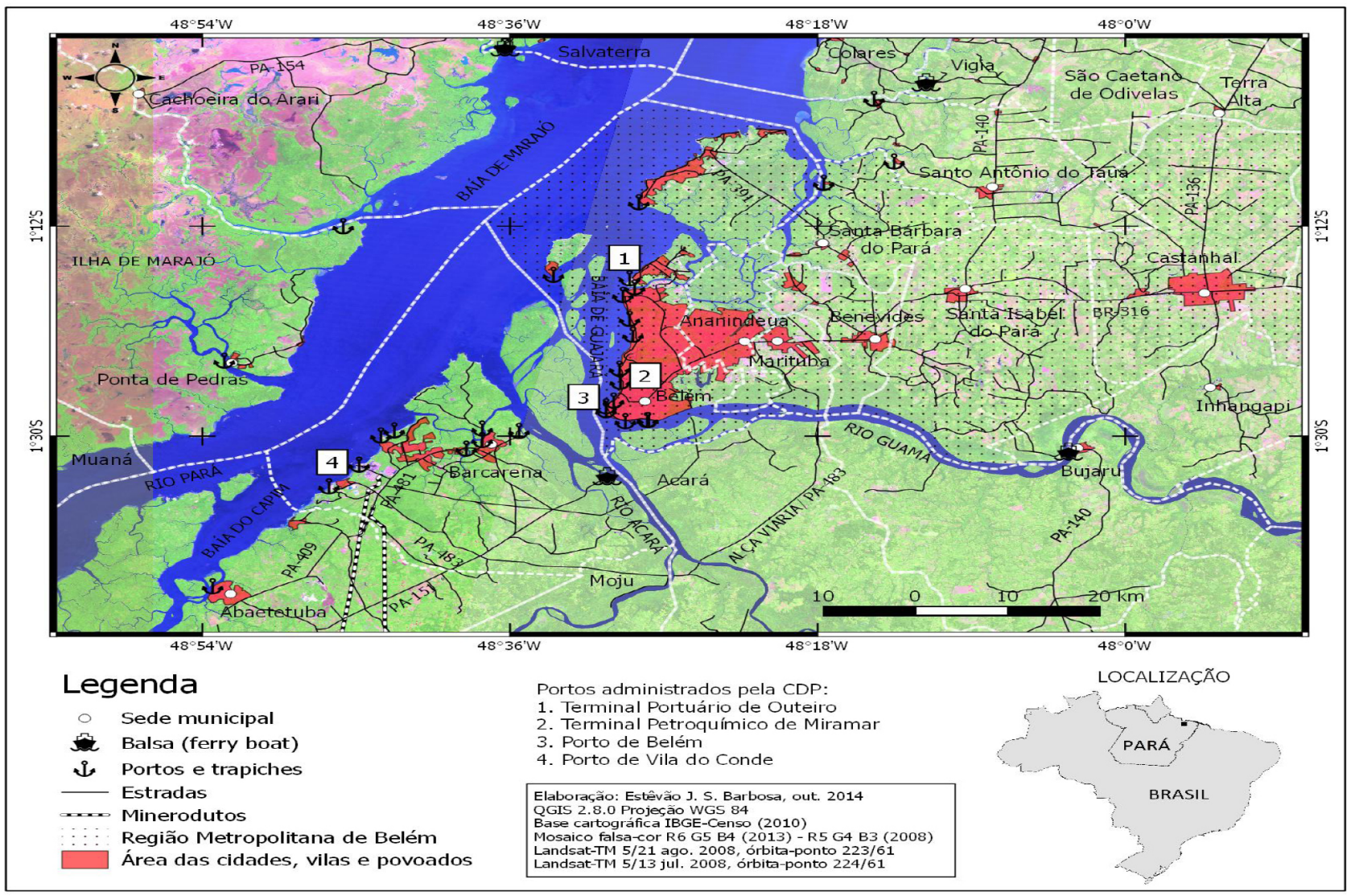

Para este último autor, o espaço relacional não se define simplesmente por seus atributos físicos, mas pelas relações que o produzem e que o inserem em articulações e interações que se originam em escalas imediatas e mediatas. Podemos acrescentar também a essa concepção de espaço a distância na sua lógica virtual e mediada por elementos que demarcam aquilo que Santos (1994) chamou de atributos do atual período histórico, a saber: a técnica, a ciência e a informação. Também partimos desses pressupostos de diferenciação (o espaço relacional e a escala topológica) para analisar a estrutura metropolitana na sua dinâmica de aglomeração e de dispersão no contexto da Amazônia oriental; esta que inclui todo o estado do Pará e onde se situa Belém, tida como a metrópole dessa porção do território brasileiro.

Consideramos, portanto, que a espacialidade dos processos sociais é compreendida tendo em vista, fundamentalmente, o espaço urbano-regional como sendo de natureza relacional. Dessa forma, concebemos a metropolização de Belém como parte da produção do espaço regional amazônico e sua condição de fronteira econômica do capital no território brasileiro. $\bigcirc$ destaque e a importância do urbano para a estruturação do espaço regional nos fazem admitir, conforme fez Becker (1990), a existência de uma fronteira urbana, definida por frentes de expansão do fenômeno urbano seja na sociedade, seja no território, como componente dessa dinâmica imposta à Amazônia nas últimas décadas.

Uma de suas é a urbanização concentrada, que contribuiu para o processo de metropolização de Belém. Além dessa expressão, alguns estudos tendem a considerar a maior importância das pequenas cidades no processo de urbanização da região, conforme fez Machado (1999), e a tendência de perda de primazia de cidades como Belém no contexto regional, conforme sugerem autores como Browder e Godfrey (2006). 
Ainda que se observem essas tendências, pensamos ser necessário relativizar tais afirmações considerando, para o caso das pequenas cidades, alguns elementos como o processo de urbanização da sociedade, da maneira como o concebeu Lefebvre (1999), que apreende o fenômeno urbano tendo em conta a modernização da sociedade e o modo de vida imposto, inclusive às pequenas cidades, em decorrência dessa mesma modernização. Além disso, para o caso da perda de primazia da metrópole belenense, é preciso considerar a necessidade de ultrapassar os recortes político-administrativos para compreender os fenômenos que definem a dinâmica de urbanização na região.

Neste último caso, mesmo admitindo a emergência de outras metrópoles no plano regional e a importância de médias e pequenas cidades como expressão do processo de urbanização na Amazônia e, ainda, a redefinição do papel e do grau de influência da cidade de Belém no contexto regional, faz-se necessário levar em conta que, ao contrário do que se poderia pensar num primeiro momento, a urbanização concentrada não perde importância no momento atual em face da expansão da fronteira econômica que se verificou no interior da região nas últimas décadas (Trindade Jr., 1998).

reforço da urbanização concentrada acontece a despeito do maior dinamismo conferido pela expansão da fronteira econômica em determinados espaços fora da órbita metropolitana, por exemplo, e que foram estimulados a crescer econômica e demograficamente (Trindade Jr., 2006). Tanto que, a partir de 2000, foram criadas nove regiões metropolitanas na Amazônia brasileira (Quadro 1), a despeito de, em alguns casos, não configurarem o processo de metropolização; outra região, a de Marabá, continua à espera de oficialização pela Assembleia Legislativa do Estado do Pará.

Considerando que a instalação de regiões metropolitanas na Amazônia Legal nem sempre se faz criteriosamente, admite-se que a metropolização regional é menos intensa do que pode sugerir a oficialização dessas novas regiões. Elas também não refletem, necessariamente, a configuração metropolitana que se faz notar hoje no contexto amazônico. $\bigcirc$ processo de desmetropolização, decorrente de menores taxas de crescimento das grandes cidades em relação a outros núcleos urbanos da mesma região (Santos, 1993), tão discutido atualmente para o espaço brasileiro, também já pode ser visto na Amazônia oriental, mas esse processo não anula a metropolização ainda em curso nessa porção da região.

A metropolização se faz presente e passa a ganhar, gradativamente, outros contornos que não se limitam a uma expansão do tecido urbano de maneira contínua e contígua ao modo das regiões metropolitanas do passado. Tal processo é marcado por (re)estruturações, rupturas e alterações, tendência essa já apontada por Santos (1993), para o caso brasileiro, desde a década de 1990.

Oespaço metropolitano de Belém é um bom exemplo dessa nova configuração metropolitana. Trata-se de uma aglomeração urbana, que, mesmo com a intensa urbanização do território no Pará, não perdeu sua importância como espaço de concentração populacional, econômica e de decisão política. A força de interesses sediados no espaço metropolitano e em sua área imediata de influência, neste último caso, foi capaz de obstaculizar, em grande parte, o projeto de criação de novos estados da federação a partir dos interesses de fragmentação política do Pará, que postulavam o reconhecimento de Carajás e Tapajós como novas unidades da federação. 


\section{Quadro 1 - Regiões Metropolitanas da Amazônia brasileira}

\begin{tabular}{|c|c|c|c|c|c|}
\hline estado (sigla) & $\begin{array}{l}\text { instrumento } \\
\text { de criação }\end{array}$ & $\begin{array}{c}\text { número } \\
\text { oficial de } \\
\text { municípios }\end{array}$ & $\begin{array}{l}\text { município } \\
\text { núcleo }\end{array}$ & $\begin{array}{c}\text { população } \\
\text { em } 2010 \\
\text { (n. hab.) }\end{array}$ & $\begin{array}{c}\% \text { na } \\
\text { população } \\
\text { estadual }\end{array}$ \\
\hline Belém (PA) & LCF 014/1973 & 7 & Belém & 2.101 .883 & 27,73 \\
\hline Grande São Luís (MA) & $C E-1989$ & 9 & São Luís & 1.496 .100 & 22,76 \\
\hline Macapá (AP) & $\begin{array}{l}\text { LCE } \\
021 / 2003\end{array}$ & 2 & Macapá & 546.152 & 81,57 \\
\hline $\begin{array}{l}\text { sudoeste maranhense } \\
(\mathrm{MA})\end{array}$ & $\begin{array}{l}\text { LCE } \\
089 / 2005 \\
\end{array}$ & 8 & Imperatriz & 351.653 & 5,35 \\
\hline Manaus (AM) & $\begin{array}{l}\text { LCE } \\
052 / 2007 \\
\end{array}$ & 8 & Manaus & 2.316 .173 & 66,48 \\
\hline capital (RR) & $\begin{array}{l}\mathrm{LCE} \\
130 / 2007 \\
\end{array}$ & 2 & Boa Vista & 324.389 & 72,01 \\
\hline central (RR) & $\begin{array}{l}\text { LCE } \\
130 / 2007 \\
\end{array}$ & 2 & Caracaraí & 29.458 & 6,54 \\
\hline sul do estado (RR) & $\begin{array}{l}\text { LCE } \\
130 / 2007 \\
\end{array}$ & 3 & Caroebe & 23.320 & 5,18 \\
\hline vale do rio Cuiabá (MT) & $\begin{array}{l}\text { LCE } \\
359 / 2009 \\
\end{array}$ & 13 & Cuiabá & 855.000 & 28,17 \\
\hline Santarém (PA) & $\begin{array}{l}\text { LCE } \\
079 / 2012\end{array}$ & 3 & Santarém & 345.502 & 4,56 \\
\hline Palmas (TO) & LE 2824/2013 & 16 & Palmas & 437.996 & 31,66 \\
\hline
\end{tabular}

fonte: Elaborado pelos autores com base em IBGE (2014a, 2014b).

siglas: CE - Constituição Estadual, LCE - Lei Complementar Estadual, LCF - Lei Complementar Federal.

A concentração urbana de Belém e seu entorno, portanto, define-se pela existência ainda do primado metropolitano no contexto regional. A configuração da metrópole, nesse caso, adquire um novo formato espacial, marcado pela dispersão urbana articulada a uma relativa diversidade de fluxos, materiais e imateriais. Não se trata, portanto, de uma malha urbana contínua, o que poderia sugerir uma discussão pautada numa escala topográfica de análise, mas de uma malha fragmentada e dispersa, cuja unidade é garantida pela intensidade de fluxos e de relações entre esses mesmos espaços descontínuos e relativamente dispersos, que merece ser compreendida a partir de uma escala topológica de interpretação.

Nesta análise, chamamos de desconcentração o processo responsável pela conformação atual da metrópole, que reúne, simultaneamente, dispersão e concentração na aglomeração urbana, sinalizando para um espaço de natureza mais complexa que se dinamiza por fluxos diversos, inclusive os imateriais, que modificam a relação do longe e do perto, aproximando lugares distantes e distanciando lugares próximos, conforme sugere Lencioni (2008).

Um dos níveis de análise do fenômeno de desconcentração aqui tratado situa-se no plano regional. Nesse aspecto, o processo de urbanização da Amazônia, e em particular da Amazônia oriental, não prescinde da urbanização concentrada, que ainda se faz presente, e do 
processo de metropolização, que é uma de suas expressões; o que nos leva a considerar que o espaço metropolitano se expande, seja por meio de um maior adensamento vertical, fato muito presente no caso belenense, seja por meio de uma expansão horizontal. Isso não se traduz necessariamente em um tecido urbano contínuo (Trindade Jr., 1998). Ainda que resguardado por certa unidade, esse mesmo tecido tende a configurar uma forma urbana dispersa e descontínua, incluindo espaços de novas atividades produtivas, como no caso daquelas instaladas no município de Barcarena. Considera-se aqui que os limites administrativos oficializados da metrópole têm pouco a ver com a dinâmica socioespacial metropolitana verificada.

Por outro lado, essa dispersão é condição que ratifica a concentração populacional em uma região urbana mais ampliada. Nesse sentido, dispersão e concentração não são vistos como elementos opostos, mas, antes, como processos que reforçam a conformação metropolitana atual, sendo articulados por uma intensidade de fluxos entre espaços que parecem não muito próximos do ponto de vista da escala topográfica. Esse entendimento pode ser estabelecido para o papel de Belém e de sua configuração metropolitana no contexto regional em que se insere.

\section{Belém e sua importância na Amazônia oriental}

No caso específico de Belém, tem sido muito comum alguns dados oficiais servirem de parâmetros para a divulgação de uma condição de perda de importância econômica e demográfica, em termos relativos, do espaço metropolitano de Belém em relação a sua região de influência, a Amazônia oriental. Isso se daria em função do crescimento econômico de outros municípios e sub-regiões relativamente distantes da área metropolitana oficialmente reconhecida, sendo parte, igualmente, do processo de desconcentração urbana presente na Amazônia oriental.

Os argumentos do declínio econômico e demográfico em termos relativos, a propósito de Belém, têm sido, inclusive, recorrentes nos discursos sobre as novas estratégias de ação e de desenvolvimento que se têm colocado nos últimos anos. Assim, diante da reestruturação do espaço regional e do novo papel assumido por Belém em face das mudanças pós-1960, com a integração econômica da Amazônia ao território brasileiro, há um discurso governamental que busca evidenciar um quadro de "declínio" de seu papel como metrópole regional.

Uma das situações apontadas assenta-se na emergência de novas metrópoles regionais. É o caso de Manaus, em decorrência da instalação da Zona Franca de Manaus (ZFM), e de São Luís, pelo papel assumido em virtude da dinamização econômica imprimida pelas diversas atividades articuladas ao Projeto Carajás - unidades de produção, porto, ferrovia etc. -, e por seu reconhecimento como patrimônio cultural da humanidade em 1997.

A importância dessas cidades, no argumento governamental, torna discutível a situação de primazia de Belém, seja pela atração de investimentos, seja pelo papel de comando da economia regional, uma vez que cidades como Manaus passaram a apresentar um dos maiores crescimentos econômicos do país. ${ }^{3}$ Ainda que Belém tenha se destacado também do ponto de

3 Em 2010, o PIB de Manaus foi de $R \$ 21.684 .450,83$ (por mil $R \$$, a preços constantes), o sexto maior do país. No ranking nacional de municípios, Belém ocupava a 27a posição, com um PIB de R\$ 8.025.926,85 (por mil) e São Luís, a 28a, com R\$7.993.677,94 (por mil). Entre as 200 primeiras posições, constavam ainda os seguintes municípios

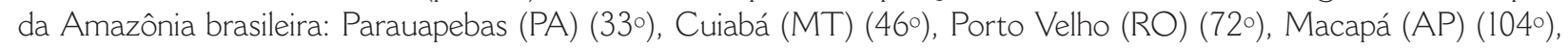

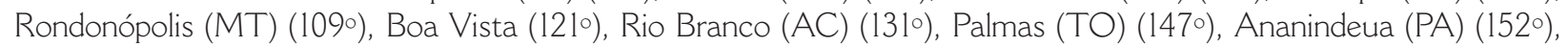
Marabá (PA) (154), Barcarena (PA) (157॰), Várzea Grande (MT) (164) e Tucuruí (193॰) (Ipea, 2014). 
vista do crescimento econômico, seu dinamismo não se compara ao de Manaus, que está entre as dez cidades que mais concentram o PIB no país, com um percentual acima de $90 \%$ do PIB entre o total de municípios do estado do Amazonas (Ipea, 2014).

Por outro lado, diferentemente das outras grandes cidades da região, que têm revelado certo grau de atratividade de investimentos, a presença de grandes projetos econômicos fora da aglomeração metropolitana de Belém tende a relativizar seu papel no contexto da participação econômica regional. Associada a isto está a situação de perda da condição de ser a "porta de entrada" da região, que foi dominante até a abertura de rodovias na Amazônia, responsável por relativizar a importância da função portuária e da navegação fluvial na região.

As tentativas de emancipação política do sul-sudeste e do oeste paraense revelam também, supostamente, a situação de fragilidade de Belém, em termos relativos, do ponto de vista político. Nesse caso, as novas lideranças políticas do estado do Pará, situadas fora da área de influência imediata de Belém e fortalecidas economicamente pelas frentes de modernização recentes no interior da Amazônia, postulam a formação de novos estados, portanto, buscando certa autonomia dentro do território nacional e sem subordinação política a Belém; sendo esse fenômeno resultado de uma espécie de balcanização política dentro do território paraense e uma forma de afirmação do poder local, como ocorre no caso do oeste paraense, onde se postula a criação do estado do Tapajós, e no sul e sudeste do Pará, onde se verifica o movimento com vistas à formação do estado de Carajás.

Ademais, a difusão e expansão de uma economia informal e a chegada de uma população migrante e empobrecida levam igualmente a uma ruptura da posição e da imagem de Belém, relativa à riqueza acumulada no período áureo da borracha, por volta de 1870 a 1920, quando a cidade foi reconhecida por seu dinamismo, modernidade e acumulação de capitais.

Tratar-se-ia-a, nesse caso, de um processo decorrente da reestruturação da rede urbana e dos novos papéis conferidos às cidades no conjunto regional, que tendem a confirmar a dinâmica de uma nova estrutura produtiva e do mercado de trabalho em sub-regiões submetidas à expansão da fronteira econômica associada a um vetor tecno-industrial (Becker, 2004) de crescimento. Tal processo tende a implicar na ruptura de antigos padrões de organização espacial, que, por sua vez, ocorre pelo caráter disseminado e pulverizado em que se manifestam os investimentos econômicos e as ações privadas e governamentais na região.

Diferentemente da Amazônia ocidental, a Amazônia oriental cresce mais que sua metrópole (Belém) devido ao dinamismo econômico imprimido a outras frações do espaço regional nos últimos anos, onde foram implantados projetos, em especial os grandes empreendimentos, que necessitam de espaços urbanos relativamente bem estruturados para o seu funcionamento, mas que não se limitam a eles, implicando em redefinições espaciais que alcançam um raio de influência relativamente significativo e que repercutem no grau de urbanização do território (Trindade Jr., 2006).

Por conta disso, os investimentos instalados na parte oriental da região amazônica em décadas precedentes se localizaram fora da região metropolitana oficial de Belém, a exemplo do Projeto Jari (município de Almeirim), do Projeto Trombetas (município de Oriximiná), do Projeto Ferro Carajás (município de Parauapebas) e do Projeto Albras-Alunorte (município de Barcarena) ${ }^{4}$.

4 Alguns desses municípios da Amazônia oriental estão entre os que apresentam maiores PIB no Brasil (cf. nota 3), destacando-se Parauapebas e Barcarena e mesmo Marabá e Tucuruí, impactados pelos projetos e reestruturações econômicas no sudeste paraense, e, fora do Pará, São Luís (MA), Macapá (AP) e Palmas (TO). 
Este último grande projeto, entretanto, desde a sua implantação, na década de 1980, tendeu a se inserir no espaço metropolitano de Belém, tal sua proximidade com capital paraense e tais os novos fluxos estabelecidos com esta em detrimento do impulso econômico e das articulações horizontais que divulgou promover em seu entorno imediato, notadamente na sub-região conhecida como Baixo Tocantins.

\section{O complexo industrial-urbano-portuário de Barcarena e suas repercus- sões socioespaciais na área de influência imediata de Belém}

O projeto Albras-Alunorte implantado no município de Barcarena, a cerca de $30 \mathrm{~km}$ de Belém em linha reta, está localizado na zona ribeirinha do estuário do rio Pará. Apesar de não muito distante da capital paraense, essa localização obstava a articulação mais intensa desse município com Belém devido à dificuldade de transporte e deslocamento, feito inicialmente por barcos e por um sistema intermodal de rodovias e balsas, tornando demorada a travessia. $\bigcirc$ funcionamento do projeto, que já surgiu integrado à cadeia mundial do alumínio e ao mercado global de commodities minerais, dependeu da interligação de infraestruturas custeadas pelo governo federal brasileiro, que atuou por meio de joint-ventures formadas por empresas japonesas e a estatal Companhia Vale do Rio Doce (CVRD) (Monteiro, 2005).

$O$ distrito industrial instalado em Barcarena foi inaugurado em $1985 \mathrm{com}$ a produção de alumínio pela Albras, junto com o porto de Vila do Conde, administrado pela Companhia Docas do Pará (CDP). Por conta de atrasos nos investimentos previstos, a produção de alumina pela Alunorte iniciou dez anos depois, em 1995. Tais empreendimentos contaram, ainda, com o fornecimento de energia subsidiada da usina hidroelétrica de Tucuruí, inaugurada um ano antes, em 1984; e com o apoio logístico de uma cidade-empresa, a Vila dos Cabanos, instalada nas imediações do distrito industrial e do porto, a cerca de $7 \mathrm{~km}$ da sede do município de Barcarena e a $40 \mathrm{~km}$ de Belém (Figura 2).

\section{Figura 2 - Complexo industrial-urbano-portuário de Barcarena}

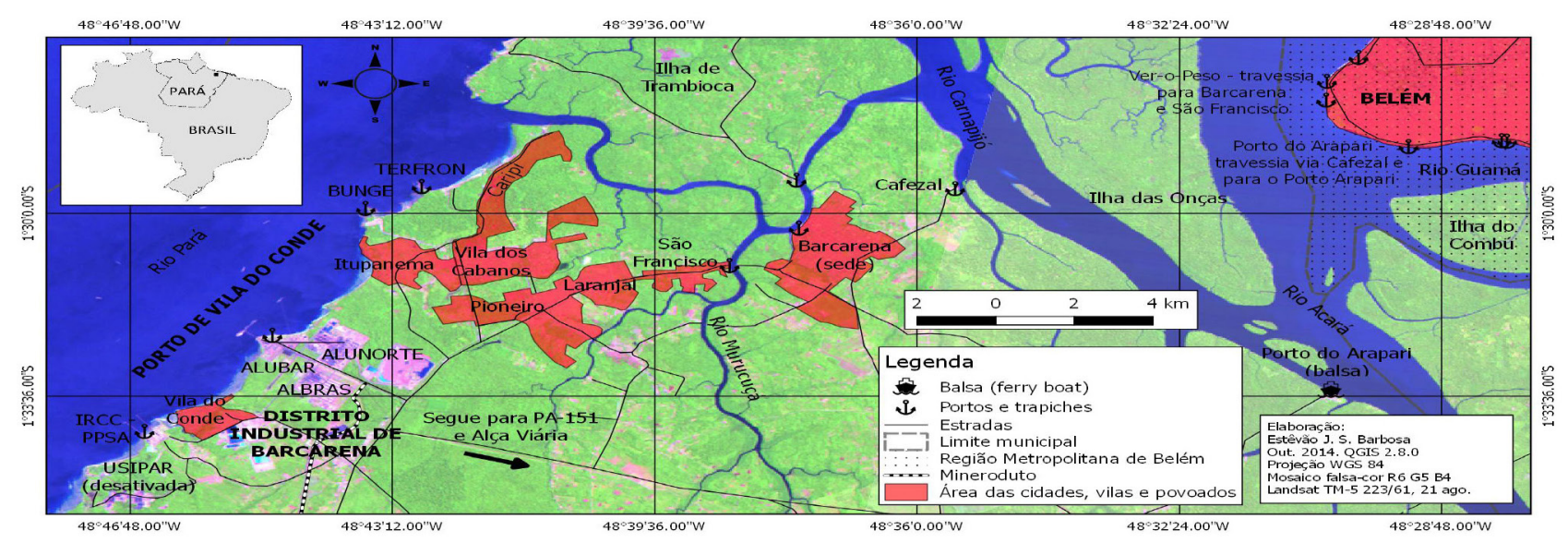

Por quase uma década, o distrito industrial de Barcarena e o porto de Vila do Conde voltaram-se exclusivamente à produção e exportação de alumina e de alumínio, passando, desde então, por sucessivas expansões, desencadeadas fundamentalmente pela privatização da CVRD, em 
1997, pela reestruturação de setores produtivos ligados à mineração e ao agronegócio na Amazônia oriental brasileira e pela consolidação de corredores de exportação no âmbito dos programas Brasil em Ação (1996-1998), Avança Brasil (1999-2002) e Programa de Aceleração do Crescimento (PAC), a partir de 2007, conduzindo a uma série de investimentos do governo federal em logística e infraestrutura (Lopes; Coelho, 2002; Monteiro, 2005; Monteiro; Coelho; Barbosa, 2011).

Um passo no sentido de verticalizar regionalmente a cadeia do alumínio foi dado com a inauguração da Alubar no ano de 1998, empresa de capital argentino que fabrica ligas de alumínio e cabos de aço; e da companhia nacional Usipar, em 2007, produzindo gusa a partir do ferro extraído de Carajás (Monteiro, 2005).

Contudo, outras cadeias produtivas foram assumindo importância na organização e funcionalidade de Barcarena, destacando-se a madeira e a pecuária, cujo embarque ainda é ocasional; e a soja, exportada pela empresa Bunge e pelo terminal da Terfron. $\bigcirc$ setor mineroindustrial, por sua vez, foi intensificado com o início das atividades da Mineração Buritirama (manganês) em 1994, da Pará Pigmentos S.A. (caulim) e da Imerys Rio Capim Caulim (caulim) em 1996 e da Bauxita Paragominas em 2007, empresa que a CVRD vendeu para a Norsk Hydro entre 2010 e 2011, incluindo também a Albras-Alunorte.

Além dos terminais da área do porto organizado, foram construídos outros três terminais privativos (IRCC, Bunge e Terfron). $\bigcirc$ distrito industrial passou a contar com novas plantas fabris e várias empresas prestadoras de serviços terceirizados, além de ser a ponta de minerodutos que escoam caulim e bauxita (Figuras 1 e 2). Novas perspectivas de crescimento estão colocadas com os corredores de exportação previstos no PAC, sobretudo as hidrovias Tocantins-Araguaia e Tapajós-Teles Pires e a ferrovia Norte-Sul (CDP, 2010).

Complementar a estes projetos foi inaugurado, no ano 2000, o Sistema de Integração do Pará (SIP), popularmente conhecido como alça viária, que consiste num conjunto de estradas e pontes que fazem a ligação rodoviária entre a BR-316 e a PA-150 articulando diretamente a RMB com os municípios do Baixo Tocantins e do Sudeste Paraense, prescindindo de qualquer tipo de transporte aquaviário (Figura 1). $\bigcirc$ SIP teve como um dos seus objetivos consolidar o complexo portuário no estuário do rio Pará (Lopes; Coelho, 2002), na medida em que o porto de Vila do Conde, moderno e com boas condições de navegabilidade, é uma alternativa ao porto de Belém, hoje considerado obsoleto, além de apresentar conflitos de uso com o entorno urbano, baixo calado e problemas constantes de assoreamento da bacia portuária e dos canais de acesso (CDP, 2014).

$\bigcirc$ incremento das atividades dinamizou o complexo industrial-urbano-portuário, conduzindo mudanças expressivas na organização do espaço local, ao mesmo tempo em que reforçaram a importância da relativa proximidade de Belém para o funcionamento da infraestrutura produtiva ali instalada. Outro fator, de importância secundária, foi o crescimento da atividade balneária ligada com o lazer da população de baixa renda após a inauguração da alça viária, sobretudo na praia do Caripi (situada a cerca de $2 \mathrm{~km}$ de Vila dos Cabanos), atraindo milhares de visitantes e motivando a instalação de segundas residências.

Esses elementos do novo arranjo espacial proposto e implantado para Barcarena, assim como as novas articulações impulsionadas com os municípios da atual Região Metropolitana de Belém, corroboram para uma nova configuração do espaço metropolitano, para além, portanto, daquilo que se reconhece como região metropolitana oficial. 
Se a dispersão metropolitana já parecia se configurar desde a década de 1990 ao se levar em conta a expansão dos assentamentos urbanos residenciais (Trindade Jr., 1998), essa mesma dispersão não se mostrava suficientemente explicada quando se consideravam as novas localizações de atividades econômicas produtivas nas adjacências de Belém.

A nova dinâmica socioespacial verificada, conforme já apontamos, está diretamente ligada a um fenômeno de concentração associado à dispersão espacial e que não constitui, necessariamente, uma malha urbana contínua e contígua. Por outro lado, essa mesma dispersão é condição que ratifica a concentração populacional e econômica na grande aglomeração belenense. Além dos sete municípios oficialmente considerados, é possível destacar outros que se mostram funcionalmente articulados à dinâmica produtiva do espaço metropolitano, a exemplo de Barcarena.

Na presente discussão, questionam-se a abrangência e as feições desse processo de metropolização considerando o espaço de incremento industrial comandado pelas empresas que atuam no município de Barcarena. As implicações dos projetos ali instalados para a reestruturação geográfica local, bem como sua articulação com a dinâmica econômica e urbana da cidade de Belém, sugerem processos que apontam para uma nova configuração metropolitana pouco considerada nos recortes oficiais.

Se Barcarena não se caracteriza como espaço contínuo de expansão residencial no conjunto metropolitano, a exemplo de outros municípios vizinhos a Belém, é possível, por outro lado, vê-lo como anteparo às migrações populacionais que se dirigiam àquela cidade e de intensificação de fluxos para com esta, tal a proliferação de atividades estimuladas pelos vários projetos aí implantados, o que sugere uma reconfiguração espacial da metrópole belenense. É nesse sentido que analisamos a importância que passou a adquirir Barcarena desde a instalação do projeto Albras-Alunorte nesse município, seguida pelos demais empreendimentos anteriormente mencionados.

Afora o porto, a cidade-empresa de Vila dos Cabanos e o entorno tornaram-se também uma importante base logística das empresas instaladas no município. Conforme afirmou Becker (1990), em grande parte, os novos núcleos urbanos planejados da Amazônia oriental configuraram-se como bases para as operações dos projetos econômicos dos anos 1970 e 1980, participando da produção de um espaço transnacional não apenas como portos e espaços industriais, mas também como lugares onde a comunicação de base eletrônica se efetua e como sedes de gerência dos diversos projetos. De um lado, todos os grandes projetos, ou "grandes objetos" (Santos, 1994) criados até 1990 preveem cidades planejadas, as "company towns", base de territórios "autossuficientes". Nesse caso, a participação do Estado foi decisiva para a instalação de Vila dos Cabanos e do porto de Vila do Conde, dentro do próprio município de Barcarena, tendo em vista o atendimento das necessidades do novo complexo industrial.

Por outro lado, nas periferias do núcleo planejado (Figura 2), há outros núcleos urbanos, já existentes - Itupanema, Vila do Conde (ou Murucupi) e São Francisco -, que passaram a se expandir ou que surgiram "espontaneamente" após o empreendimento - Laranjal, Pioneiro etc. - e cresceram com a chegada de mão de obra pouco qualificada e móvel e mesmo com a força de trabalho dispensada após o término das instalações do grande empreendimento ou que foi remanejada da área necessária para a instalação das obras de infraestrutura do distrito industrial e seu porto anexo. 
No caso de Barcarena, investimentos sucessivos visando a expansão de infraestruturas motivaram vários episódios de migração desde o fim dos anos 1970 (Monteiro; Coelho; Barbosa, 2011), tendo sido um de seus reflexos a formação e a expansão de espaços urbanos segregados, marcados por condições de vida precárias, principalmente no entorno de Vila dos Cabanos. $O$ resultado do aumento populacional foi o surgimento, em Barcarena, da quinta maior aglomeração populacional no entorno de Belém (Figura 1), com cerca de 73 mil habitantes em 2010, atrás apenas de Ananindeua (470,8 mil hab.), Castanhal (149,8 mil hab.), Marituba (107,2 mil hab.) e Abaetetuba (80,8 mil hab.) (IBGE, 2014c).

No entorno imediato do distrito industrial e especialmente da Vila dos Cabanos, localizam-se a maioria dos assentamentos urbanos "espontâneos" hoje existentes no município de Barcarena. Esses tipos de assentamentos, conforme sustenta Piquet (1998, p. 36), "ainda que espacialmente possam ser núcleos separados, funcionalmente constituem um único núcleo urbano. Embora essa interdependência seja real, não se traduz em uma tendência à equalização quanto à disponibilidade dos bens de consumo coletivo".

A cidade-empresa serviria de moradia aos funcionários das indústrias e de suporte técnico para algumas operações da empresa. Inicialmente, foi concebido para atender às necessidades residenciais, comerciais e de serviços dos funcionários da Albras-Alunorte e do porto de Vila do Conde e, posteriormente, deveria atender a todo o distrito industrial de Barcarena, de acordo com as propostas de dinamização econômica para a microrregião na qual se insere.

Uma integração cidade-empresa estava prevista no plano urbanístico de Vila dos Cabanos. Este foi elaborado pelo escritório de consultoria Arquiteto Joaquim Guedes \& Associados, nos moldes de outras cidades-empresa construídas para fins semelhantes. Entretanto, a clássica integração cidade-empresa procurou ser amenizada com a filosofia de "cidade aberta", prevista para Vila dos Cabanos, contrapondo-se, em tese, a outras concepções de cidades de empresas até então instaladas na Amazônia, tidas como cidades fechadas, altamente controladas e autossegregadas (Trindade Jr.; Chagas, 2002).

As possibilidades de inserção e de integração da nova cidade seriam diversas, não devendo se reduzir ao apoio logístico da empresa motivadora de sua existência. Com capacidade para comportar cerca de 70.000 habitantes, ocuparia uma posição de destaque diante das cidades próximas. O Plano Urbanístico (Sudam, 1980) previa, ainda, os mais variados equipamentos urbanos, de serviços e comerciais (Trindade Jr.; Chagas, 2002).

Em análise que confronta o plano urbanístico com a organização atual do espaço, Chagas (1999) destaca alguns elementos para entender a dimensão espacial de Vila dos Cabanos. Mostra, por exemplo, que grande parte do que foi concebido no plano acabou não sendo posto em prática. A Vila contava, em 2010, com uma população aproximada de 7.000 habitantes (IBGE, 2014b), muitíssimo abaixo do esperado, levando, assim, a não implantação dos equipamentos urbanos inicialmente previstos. Sua capacidade de polarização, que deveria abranger a microrregião do Baixo Tocantins, acabou não se concretizando, definindo assim uma articulação muito maior com os municípios integrantes da RMB, configurando mesmo um espaço funcionalmente articulado com esta. 
Essa articulação pode ser comprovada também pelo papel que o porto de Vila do Conde passou a exercer no conjunto metropolitano, estando localizado a cerca de $120 \mathrm{~km}$ do porto de Belém, por via rodoviária (CDP, 2014). Observa-se uma intensidade de fluxos que Barcarena estabelece com os municípios oficialmente inseridos na área metropolitana de Belém, sendo comum a presença de migração pendular de trabalhadores das empresas ali situadas que moram em Belém e que se deslocam durante o dia para Barcarena para exercerem seus postos de trabalho nas diversas empresas ali situadas. $\bigcirc$ mesmo acontecendo no sentido inverso.

A intensidade de fluxos se mostra hoje ainda mais favorecida pela construção da alça viária (PA-483). Três modalidades de transporte se fazem presentes hoje na articulação Belém-Barcarena: o fluvial, que ainda permanece, o rodo-fluvial, que articula os modais balsa-rodovia ou barco-rodovia; e o rodoviário, que se faz por meio da alça viária, e (Figura 2). Neste último caso, houve o reforço de fluxos rodoviários com a RMB, como se pode deduzir dos dados de tráfego agregados para o Baixo Tocantins (Pará, 2010). Em 2009, cerca de 89\% desses fluxos tinham como origem ou destino os municípios metropolitanos.

\section{Tabela 1 - População absoluta e taxa de crescimento médio anual (TCMA) no município de Barcarena, decênio 2000-2010}

\begin{tabular}{lccc}
\hline localidade & 2000 & 2010 & TCMA \\
\hline Barcarena (sede municipal) & 23.190 & 29.378 & $2,39 \%$ \\
\hline São Francisco e entorno & 2.121 & 2.626 & $2,16 \%$ \\
\hline Laranjal e Pioneiro & 5.925 & 15.527 & $10,11 \%$ \\
\hline Vila do Conde & 4.577 & 6.919 & $4,22 \%$ \\
\hline Vila dos Cabanos e entorno & 7.140 & 11.411 & $4,80 \%$ \\
\hline Itupanema & 462 & 7.100 & $31,42 \%$ \\
\hline & & & \\
\hline Barcarena - total & 63.268 & 99.859 & $4,67 \%$ \\
\hline população urbana & 43.415 & 72.961 & $5,33 \%$ \\
\hline população rural & 19.853 & 26.898 & $3,08 \%$ \\
\hline & & & \\
\hline taxa de urbanização (\%) do município de Barcarena & 68,62 & 73,06 & \\
\hline
\end{tabular}

fonte: Elaborada pelos autores, com base em IBGE (2014c).

Uma integração de fatores - atração de mão de obra pouco qualificada, maior facilidade de transporte e articulação com Belém e, secundariamente, o incremento das atividades de lazer e turismo - pode, assim, estar motivando um expressivo crescimento de espaços periféricos de residência em Barcarena, processo este que assume feições metropolitanas. Neste sentido, as taxas de crescimento médio anual da população no decênio 2000-2010 (Tabela 1) foram superiores às taxas nacional (1,18\%) e estadual (2,00\%). Em nível municipal, Barcarena $(4,67 \%)$ se aproxima dos municípios metropolitanos, especialmente os situados na borda da RMB, a exemplo de Santa Bárbara do Pará (4,18\%), Marituba (3,82\%), Benevides (3,81\%) e Santa Isabel do Pará (3,24\%). 


\section{À guisa de conclusão: uma nova configuração metropolitana?}

Muito mais que contribuir para a redução do primado urbano até então expressivo na Amazônia oriental, a importância do complexo industrial-urbano-portuário implantado em Barcarena e do processo de urbanização que lhe sucedeu parece ter reforçado a concentração que, por meio da dispersão de assentamentos urbanos e da consolidação de uma nova área portuária, amplia a dimensão metropolitana de Belém, redimensionando seu papel de metrópole regional.

Conforme o que estabelecia o Plano Urbanístico de Barcarena (Sudam, 1980), o complexo industrial-urbano-portuário, por meio de sua cidade planejada, seria um componente básico da nova infraestrutura urbana em Barcarena para as empresas de alumínio e alumina e de outras empresas que viriam a se instalar posteriormente no município. Assim, de acordo com as propostas de dinamização econômica para a microrregião em que se insere, deveria atender a todo o distrito industrial de Barcarena.

A ideia de polarização presente no plano e o papel do novo núcleo como uma localidade central se mostram distantes daquilo que foi previsto. Por outro lado, a RMB, que até a década de 1970 era constituída apenas por Belém e Ananindeua, expandiu-se sensivelmente nos anos seguintes, com a inclusão de outros municípios na estrutura metropolitana oficial. Por ocasião da nova configuração observada a partir da década de 1990, foi igualmente prevista no pré-projeto de lei para esse fim a inclusão, além de Santa Isabel do Pará, do município de Barcarena. Este último, porém, não foi efetivamente considerado integrante da RMB até o presente momento.

Não obstante a interpretação diferenciada dos legisladores estaduais, a situação hoje, especialmente com o crescimento do porto de Vila do Conde e com a construção da alça viária, revela, sem dúvida alguma, uma nova configuração do espaço metropolitano belenense. Nessa configuração, além dos municípios já incluídos oficialmente, cabe destacar a importância de Barcarena, não exatamente por uma mancha urbana única, como acontece com outros municípios desse contexto socioespacial, mas essencialmente pelas relações que foram estabelecidas, intensificadas e reforçadas a partir do grande empreendimento ali instalado e que pressupõe não apenas os fluxos considerados materiais.

O exemplo de Barcarena parece interessante nesse caso, pois tende a reafirmar a importância de Belém e da RMB no contexto regional ainda como primado metropolitano. Primeiro, pelo fato de que os estudos sobre o crescimento da RMB, quando baseados apenas nas estatísticas oficiais, desconsideram a área metropolitana expandida, que se soma continuamente ao processo de concentração verificado nos municípios formadores da RM oficial. Segundo, por não se levar em conta também a área de influência imediata de Belém. Nesta, há um razoável número de núcleos urbanos que apresentam crescimento econômico e populacional, seja pela implantação de projetos econômicos, como no caso de Barcarena, seja pelas condições da área de influência imediata de Belém, um espaço relativamente bem consolidado.

No contexto amazônico, essa é a área com maior coesão interna (Magnano, 1989), sendo que os diversos municípios que a compõem ligam-se à capital por uma rede de transportes e comunicação relativamente bem estruturada, intensificando, com isso, material e virtualmente as relações regionais, que, mesmo fora da região metropolitana expandida, conservam um significativo grau de dependência de atividades, serviços e empregos existentes em Belém. 
Portanto, é um crescimento que não prescinde dos fatores de aglomeração apresentados por Belém. Assim sendo, e confirmando o que já acreditava Rodrigues (1996), é inquestionável que está ocorrendo um processo brutal de concentração urbana nas cidades contíguas a Belém. $\bigcirc$ espraiamento da urbanização dessa cidade amplia cada vez mais sua influência para além de seus limites territoriais, aprofundando um processo de expansão que, ao mesmo tempo, reforça uma concentração dispersa da qual Barcarena parece fazer parte.

\section{Referências}

BECKER, B. Amazônia: geopolítica na virada do III milênio. Rio de Janeiro: Garamond, 2004.

Amazônia. São Paulo: Ática, 1990.

BROWDER, J. O.; GODFREY, B. J. Cidades da floresta: urbanização, desenvolvimento e globalização na Amazônia brasileira. Manaus: Edua, 2006.

CDP. COMPANHIA DOCAS DO PARÁ. Portos e terminais. Belém: CDP, 2014. Disponível em: <http://www.cdp.com.br/>. Acesso em: 10 jun. 2014.

Relatório 03: Empreendimento: Atualização do Plano de Desenvolvimento e Zoneamento do Porto de Vila do Conde, situado no município de Barcarena. Belém: CDP, 2010.

CHAGAS, C. A. N. Vila dos Cabanos: representações do espaço e práticas espaciais em uma company-town da Amazônia. Trabalho de Conclusão de Curso (Graduação em Geografia) - Centro de Filosofia e Ciências Humanas, Universidade Federal do Pará, Belém, 1999.

HARVEY, D. A justiça social e a cidade. São Paulo: Hucitec, 1980.

IBGE. INSTITUTO BRASILEIRO DE GEOGRAFIA E ESTATÍSTICA. Municípios por regiões metropolitanas. IBGE, 2014a. Disponível em <http://downloads.ibge.gov. br/downloads_geociencias.htm>. Acesso: 29 out. 2014.

Território A-Z: Região Metropolitana (posição vigente em 31.12.2013). IBGE, 2014b. Disponível em: <http://www.sidra.ibge.gov.br/bda/territorio/tabunit. asp? $\mathrm{n}=7 \varepsilon_{\mathrm{t}}=2 \varepsilon_{\mathrm{z}}=\mathrm{t} \varepsilon \mathrm{o}=4>$. Acesso: 29 out. 2014.

Censo Demográfico 2010. IBGE, 2014c. Disponível em: <http://www.sidra.ibge. gov.br/bda/tabela/listabl.asp?c=202Ez=tEo=25>. Acesso: 29 out. 2014.

IPEA. INSTITUTO DE PESQUISAS APLICADAS. Contas nacionais: PIB a preços constantes. Ipea, 2014. Disponível em: <http://www.ipeadata.gov.br/>. Acesso em: 29 out. 2014.

LEFEBVRE, H. A revolução urbana. Belo Horizonte: Editora da UFMG, 1999.

LENCIONI, S. Concentração e centralização das atividades urbanas: uma perspectiva multiescalar. Reflexões a partir do caso de São Paulo. Revista de Geografía Norte Grande, Santiago de Chile, n. 39, p. 7-20, 2008. 
LOPES, A.; COELHO, I. Reorientando olhares sob o estuário: a importância portuária das cidades estuarinas na Amazônia. In: SIMPÓSIO AMAZÔNIA, CIDADES E GEOPOLÍTICA DAS ÁGUAS, 2002. Anais... Belém: Ufpa/MPEG/Fadesp, 2003, p. 6367.

MACHADO, L. O. Urbanização e mercado de trabalho na Amazônia brasileira. Cadernos IPPUR, v. XIII, n. 1, p. 109-138, jan./jul.1999.

MAGNANO, A. A estrutura do espaço regional. In: INSTITUTO BRASILEIRO DE GEOGRAFIA E ESTATÍSTICA. Geografia do Brasil: região Norte. Rio de Janeiro, 1989. p. 275-307. v. 3.

MONTEIRO, M. A. Meio século de mineração industrial na Amazônia e suas implicações para o desenvolvimento regional. Estudos Avançados, v. 19, n. 53, p. 187-207, 2005. ; COELHO, M. C. N.; BARBOSA, E. J. S. Fronteira, corredores de exportação e rede urbana na Amazônia oriental brasileira. Geographia, v. 13, n. 26, p. 37-65, 2011.

PARÁ. Assembleia Legislativa. Projeto de Lei n. 167/2012. Belém: Alepa, 2012.

Secretaria de Estado de Transportes. Plano Estadual de Logística e Transportes. Belém: Setran, 2010.

PIQUET, R. Cidade-empresa na Amazônia: presença na paisagem urbana brasileira. Rio de Janeiro: Jorge Zahar, 1998.

RODRIGUES, E. B. Aventura urbana: urbanização, trabalho e meio ambiente em Belém. Belém: Naea, 1996.

SANTOS, M. Técnica, espaço, tempo: globalização e meio técnico-científico informacional. São Paulo: Hucitec, 1994.

A urbanização brasileira. São Paulo: Hucitec, 1993.

SUDAM. SUPERINTENDÊNCIA PARA O DESENVOLVIMENTO DA AMAZÔNIA. Plano Urbanístico de Barcarena. São Paulo: Guedes e Associados, 1980. 3 v.

TRINDADE JR., S.-C. C. Grandes projetos, urbanização do território e metropolização na Amazônia. Revista Terra Livre, São Paulo, v. 26, n. 1, p. 177-194, jan./jun. 2006.

A cidade dispersa: os novos espaços de assentamentos em Belém e a reestruturação metropolitana. Tese (Doutorado em Geografia Humana) - Faculdade de Filosofia, Letras e Ciências Humanas, Universidade de São Paulo, São Paulo, 1998.

; S.-C. C.; CHAGAS, C. A. N. A company town do alumínio: concepção e práticas espaciais. In: TRINDADE JR., S.-C C.; ROCHA, G. M. (Org.). Cidade e empresa na Amazônia: gestão do território e desenvolvimento local. Belém: Paka-Tatu, 2002. p. 195-235. 